Revista Bioética

\title{
PESQUISA
}

\section{Humanidades: ensino de "nova" dimensão ética na educação médica}

Carlos Alberto Severo Garcia Júnior

Departamento de Ciências da Saúde, Universidade Federal de Santa Catarina, Araranguá/SC, Brasil.

\section{Resumo}

O objetivo deste estudo é apresentar o processo de formação ética por meio da disciplina Humanidades Médicas do curso de medicina de instituição de ensino superior do Sul do Brasil. Trata-se de pesquisa qualitativa realizada com 28 alunos matriculados entre o 10 e o 70 período. Os dados foram coletados em grupos focais, e os resultados, obtidos por análise de conteúdo, foram divididos em duas categorias temáticas: produção de si e de práticas relativas à dimensão ética da medicina; e propostas de mudança na formação humanística. Conclui-se que é necessário identificar os problemas éticos do processo de ensino-aprendizagem, desenvolver oportunidades para outras formas de conexão entre docentes e discentes e problematizar questões inerentes à ética médica.

Palavras-chave: Bioética. Educação médica. Estudantes de medicina. Educação superior. Brasil.

\section{Resumen}

\section{Humanidades: enseñanza de una "nueva" dimensión ética en la educación médica}

El objetivo de este estudio es presentar el proceso de formación ética a través de la asignatura de Humanidades Médicas de la carrera de medicina de una institución de educación superior en el Sur de Brasil. Se trata de una investigación cualitativa llevada a cabo con 28 estudiantes de medicina entre el 1.ำy el 7.ำ período. La recolección de datos se realizó a través de grupos focales, y los resultados, obtenidos por análisis de contenido, se dividieron en dos categorías temáticas: producción de uno mismo y prácticas relacionadas con la dimensión ética de la medicina; y propuestas de cambio en la formación humanística. Se concluye que es necesario identificar los problemas éticos del proceso de enseñanza-aprendizaje, desarrollar oportunidades para otras formas de conexión entre docentes y estudiantes y problematizar cuestiones inherentes a la ética médica.

Palabras clave: Bioética. Educación médica. Estudiantes de medicina. Educación superior. Brasil.

\section{Resume}

\section{Humanities: teaching a "new" ethical dimension in medical education}

This study presents the process of ethical formation through the Medical Humanities subject of a medical undergraduate program in Southern Brazil. This is a qualitative research carried out with 28 medical students between the 1st and 7th periods. Data collection took place by focus groups and the results, obtained by content analysis, were divided into two thematic categories: production of self and of the ethical dimension in medical education; and proposals of changes in "humanistic" training. We concluded that it is necessary to identify the ethical problems present in the teaching-learning process itself, develop opportunities for other means of connection between professors and students and discuss issues inherent to medical ethics.

Keywords: Bioethics. Education, medical. Students, medical. Education, higher. Brazil. 
Nas duas últimas décadas, o tema da humanização em saúde ganhou destaque no Brasil, em decorrência das dificuldades de acesso e da baixa qualidade dos serviços. Tal precariedade se deve principalmente à desumanização e "tecnificação" da assistência, associadas à aceleração da produção e do consumo ${ }^{1}$. Como resposta, aumentaram as tentativas de formular e reconfigurar as relações humanas no cuidado em saúde, sobretudo no âmbito médico.

As propostas acabaram consolidando movimento contra-hegemônico para superar a fragilidade das relações humanas na assistência. Em 2000, a 11a Conferência Nacional de Saúde apontava a necessidade de ampliar o acesso, melhorar a qualidade e humanizar a atenção à saúde, atribuindo ao poder público a responsabilidade de garantir a cidadania ${ }^{2}$. Em 2003, a Política Nacional de Humanização da Atenção e Gestão no Sistema Único de Saúde buscou construir política pública baseada na indissociabilidade entre atenção e gestão e na valorização do protagonismo, da corresponsabilidade e da autonomia dos sujeitos e coletividades ${ }^{3}$.

Nesse mesmo período, o currículo médico foi reorganizado, incorporando demandas da sociedade. Em 2001, as novas Diretrizes Curriculares Nacionais (DCN) apontaram a necessidade de incluir dimensões éticas e humanísticas na formação dos profissionais ${ }^{4}$. Quase duas décadas depois, percebe-se que as DCN valorizaram as ciências humanas e sociais ao estabelecê-las como eixos transversais ${ }^{5}$.

Como aponta Rios ${ }^{6}$, na medicina convergem saberes de diversos campos do conhecimento, como sociologia, história, antropologia, artes, filosofia, educação, linguística e bioética. Assim, haveria uma área das "humanidades médicas", cujo objeto de estudo são o desenvolvimento, as características, necessidades e consequências das relações humanas na medicina, com ênfase na interação da realidade com a formação. Todavia, apesar da conformação desse campo e dos avanços alcançados pelas DCN, ainda há muitas dificuldades a serem enfrentadas, como falta de integração com disciplinas clínicas, conteúdo programático descolado de problemas reais da medicina assistencial, metodologias de ensino inadequadas, professores despreparados ${ }^{7}$.

As humanidades médicas ainda conformam território difuso, cujos limites estão sendo construídos e experimentados. O desafio de consolidar a humanização da saúde extrapola questões metodológicas e a integração de disciplinas. É no campo das relações, do encontro, do trabalho vivo, em ato, que discentes e docentes de fato atuam, interagem e afetam uns aos outros $^{8-10}$. Assim, nesta pesquisa, procura-se apresentar como ocorre na prática o processo de formação ética no curso de medicina de instituição de ensino superior do Sul do Brasil.

\section{Método}

Trata-se de pesquisa qualitativa que busca desvelar processos sociais, significados, motivos, aspirações, atitudes, crenças e valores que envolvem o campo das humanidades médicas. A abordagem descritiva tem como finalidade estudar características de determinado grupo e sua distribuição, captando opiniões e associando variáveis ${ }^{11}$. Formaram-se grupos focais ${ }^{12}$, e os dados coletados foram examinados pelo método da análise de conteúdo de tipo temática, que identifica significados a partir das etapas de pré-análise, exploração, tratamento e interpretação do texto das entrevistas ${ }^{11}$.

A pesquisa foi conduzida na Universidade do Vale do Itajaí (Univali), instituição privada de ensino superior fundada em 1964, localizada no município de Itajaí/SC. O curso de medicina foi implantado na universidade em 1998, e 29 turmas foram formadas até dezembro de 2018. A matriz curricular tem carga horária total de 8.295 horas e oferece dois eixos transversais: técnico, voltado à formação geral, e atitudinal, que considera aspectos éticos, humanísticos e sociais da prática médica ${ }^{13}$.

Foram entrevistados 28 discentes matriculados entre o 1 응 e 70 período do curso de medicina, em que se concentram as disciplinas de humanidades. A quantidade de participantes foi definida de modo que a amostra contivesse ao menos quatro estudantes de cada um desses sete semestres, dois do sexo feminino e dois do masculino, sorteados a partir da lista de matrícula. A divisão entre sexos buscou dar abrangência e paridade à pesquisa.

O critério utilizado para definir o número de grupos foi a saturação de dados, alcançada no quarto grupo focal, com abrangência do problema investigado em diferentes dimensões. Utilizou-se tópico-guia que, além de ajudar a conduzir as entrevistas, funcionou como esquema preliminar para analisar as transcrições ${ }^{12}$. As falas foram gravadas e posteriormente transcritas, preservando sempre a identidade dos participantes. Os dados foram coletados em agosto de 2018, e o estudo foi aprovado pelo Comitê de Ética em Pesquisa da Univali. 


\section{Resultados e discussão}

Da análise dos dados obtidos na pesquisa emergiram duas grandes categorias temáticas: produção de si e de práticas relativas à dimensão ética da formação médica; e propostas de mudança na formação humanística. Ambas são analisadas a seguir.

\section{Dimensão ética da formação médica}

Os achados deste estudo confirmam a importância das ciências humanas ${ }^{9}$ e do paradigma ético-estético-político para a formação em medicina. Compreende-se "ética" como o compromisso dos discentes, docentes e instituição de ensino com a educação médica. "Estética" diz respeito ao processo criativo e sensível envolvido na produção do cuidado e da subjetividade dos envolvidos. E "política" refere-se à organização social e institucional das práticas de formação.

Na universidade estudada, as humanidades médicas tornaram-se eixo curricular a partir de 2015. Anteriormente, havia as disciplinas Ética Médica e Bioética. Em seu artigo, Grisard ${ }^{14}$ recupera parte da história do processo de institucionalização dessas duas matérias na Univali. Conforme o autor, foram diversas as razões para incluir, em forma crescente, os conteúdos da ética médica e bioética no curso de graduação em medicina da Univali. Não foram argumentos de modismo, pois este inexiste quando se trata de ensino da ética médica nas escolas de medicina. Não foram, certamente, argumentos para ser diferente, nem para agradar a qualquer instituição oficial, acadêmica ou não, ou entidades médicas - as quais, com raríssimas exceções, jamais se preocuparam com o ensino de ética médica ${ }^{15}$.

Ainda que o autor destaque o caráter "apolítico" da mudança no currículo, sem vínculos institucionais ou influência de "modismos", é inevitável não associar essa transformação ao movimento protecionista e à questão da identidade médica. $\mathrm{E}$ a vivência de Grisard ${ }^{14}$ em outro espaço institucional o Conselho Regional de Medicina de Santa Catarina-, testemunhando diversas denúncias de infração ética e carência de conhecimento, talvez o tenha levado a estimular a inclusão dessas disciplinas.

As mudanças das DCN ${ }^{4}$ em 2001 - que estabeleceram princípios, fundamentos e finalidades para a formação em medicina e um perfil ideal de egresso foram auspiciosas, pois permitiram aproximar os ministérios da Saúde e da Educação. Anos depois, com a ampla adesão ao documento em projetos pedagógicos, mostra-se elevado o compromisso - explícito ou implícito - com a formação de profissionais críticos e reflexivos, de modo a produzir "boa imagem" do curso ${ }^{16}$.

Em 2015, com a implantação do novo projeto pedagógico do curso de medicina da Univali, o eixo de humanidades médicas passa a integrar o currículo ${ }^{13}$, ganhando credibilidade entre docentes e discentes. Nesse momento fica estabelecido que as disciplinas do eixo atravessarão sete períodos, totalizando 210 horas. 0 nome da disciplina permanece o mesmo em cada semestre ("Humanidades Médicas"), mas cada período tem ementa e características próprias (Quadro 1).

Quadro 1. Períodos, ementas, carga horária e créditos das disciplinas de humanidades médicas

\begin{tabular}{|c|c|c|}
\hline Período & Ementa & Carga horária e créditos \\
\hline 10 & $\begin{array}{l}\text { Saúde no contexto social, na análise histórica e cultural. Medicina: diferentes } \\
\text { concepções, muitos olhares. Humanização e saúde. }\end{array}$ & \multirow{7}{*}{30 horas -2 créditos } \\
\hline 20 & $\begin{array}{l}\text { O ser médico na evolução sociocultural. A modernidade e a concepção do ser } \\
\text { médico. A história da clínica. O médico cientista, o especialista, o clínico, o } \\
\text { médico de família. }\end{array}$ & \\
\hline $3 ㅇ$ & $\begin{array}{l}\text { A relação do homem com o processo saúde-doença. O trabalho em equipe } \\
\text { interdisciplinar. A relação pessoa-médico. Encontros na clínica. }\end{array}$ & \\
\hline 40 & $\begin{array}{l}\text { Cuidado: aspectos filosóficos, antropológicos, psicológicos e sociológicos. Ética } \\
\text { do cuidado e princípio da responsabilidade. O cuidado no contexto familiar, } \\
\text { nos serviços de saúde, nas políticas públicas e com o meio ambiente. }\end{array}$ & \\
\hline 5운 & $\begin{array}{l}\text { Bioética: aspectos históricos, legais, filosóficos e antropológicos. Bioética: a } \\
\text { pessoa doente, a comunidade, os serviços de saúde. Bioética na pesquisa e } \\
\text { suas relações com as questões éticas. Bioética e direitos humanos. }\end{array}$ & \\
\hline 60 & $\begin{array}{l}\text { Deontologia. O Código de Ética Médica. A epistemologia do Código. Direitos e } \\
\text { deveres da profissão médica. }\end{array}$ & \\
\hline 70 & $\begin{array}{l}\text { Considerações sobre o nascimento, a vida, o adoecer, envelhecer e sobre a } \\
\text { morte. Questões polêmicas e dilemas éticos na prática médica. Tanatologia e } \\
\text { comunicação de más notícias. }\end{array}$ & \\
\hline
\end{tabular}

Fonte: adaptado de Universidade do Vale do Itajai $^{17}$. 
Os desafios para a formação médica vão desde déficits de escolarização prévia, persistentes na formação profissional, até a duração do curso, que impõe a necessidade de adquirir habilidades psicomotoras, cognitivas e afetivas em apenas seis anos e com currículo focado em conteúdos biológicos, em detrimento de aspectos humanísticos ${ }^{18}$. No entanto, as mudanças no perfil ideal do médico, deslocando o enfoque da doença para a promoção da saúde, têm reverberado na educação, confrontando os paradigmas flexneriano e da integralidade ${ }^{19}$. Essas transformações se baseiam em recomendações de foros internacionais e nacionais, com diferentes alianças ${ }^{20}$.

Ao frequentar a escola médica, o estudante passa por processo de socialização em que a experiência sociocultural se integra ao aprendizado de aspectos técnicos ${ }^{16}$. Esse processo é complexo, e não por acaso os discentes declaram se sentir desamparados para enfrentar as responsabilidades inerentes à profissão. A formação reside: 1) na correlação entre ato, fala e atitude, independentemente do tema ou conteúdo abordado; 2) na valorização de metodologias e técnicas pedagógicas abertas à experimentação e à expressão; e 3) na conexão com a realidade e no desenvolvimento de senso crítico. Esses três aspectos são desafios e temas permanentes nos debates sobre a dimensão ética da medicina, sobretudo na constituição de fronteiras e da interdisciplinaridade.

Em falas coletadas nos grupos focais, pode-se constatar contradições do relacionamento entre discente, docente e escola médica:

"Muitas vezes o professor tem um lugar de saber e autoridade. Teria que ter um empoderamento dos alunos em buscar o conhecimento, para saber se está certo ou errado. Eu acho que dentro da medicina a gente tem a questão do tempo. A gente não tem tempo suficiente para fiscalizar tudo que o professor fala, porque eu tenho que decorar muitas outras coisas, doses de uma medicação, por exemplo, porque cai numa prova. Eu não questiono, porque não tenho esse poder. Eu gostaria, pois eu duvido de algumas coisas" (Grupo Focal 3).

Compartilhar a concepção ética do processo ensino-aprendizagem não protege o aluno de equívocos e angústias inerentes a esse processo. Nos grupos focais, os discentes consideraram que a disciplina gira em torno da avaliação do desempenho e interrogaram-se sobre a possibilidade de se comprometer com o tema sem adotar atitude negligente. Os participantes questionaram a contradição de serem avaliados em processo qualitativo que resulta em "nota" (quantitativa) e propuseram "metodologias ativas", capazes de facilitar o aprendizado. Foi sugerido o uso de instrumentos que pudessem conectar estudantes e conteúdo, como notícias e matérias de revista, rodas de conversa, redação de mensagens para colegas de outros períodos, videoaulas, filmes curtos e documentários, convites a profissionais de outras áreas e projetos de extensão e pesquisa.

\section{Mudanças na formação humanística}

"Formação humanística" refere-se à transmissão de valores e atitudes que integra dimensões psicológicas, etnorraciais, socioeconômicas, culturais e ambientais com a dimensão biológica. É importante que haja disciplina regular para esclarecer dilemas, problemas e conflitos éticos na formação e prática profissional. No entanto, os temas atrelados às humanidades devem ser discutidos em todo o curso médico, sobretudo nas especialidades clínicas e cirúrgicas, em que se tem contato direto com pessoas e suas experiências de adoecimento.

Conforme fala dos estudantes, "nas humanidades médicas há muitos outros assuntos para serem abordados que a gente não vai ter na clínica, por exemplo" (Grupo Focal 1). Tais assuntos foram indicados nos grupos focais, permitindo que ideias e intenções fossem compartilhadas. A sistematização dessas propostas, com os temas organizados em ementas de períodos, encontra-se no Quadro 2.

A diversidade de temas indica a abrangência de interesses da disciplina, mas por si só não garante a inovação e integralidade da formação médica. Um dos obstáculos a se ultrapassar é a carga horária reduzida das humanidades médicas em comparação com outras áreas. Conseguir espaço em currículo já sobrecarregado e a falta de consenso sobre conteúdos e métodos pedagógicos são barreiras para a integração das humanidades ${ }^{8}$.

Alguns discentes consideram que a teoria muitas vezes é "linda", mas falta colocá-la em prática - apontamento genérico que ignora a grande quantidade de médicos e docentes de medicina que integram as humanidades médicas em seu trabalho. Por outro lado, a opinião dos alunos destaca a necessidade de concretizar o aprendizado teórico em atividades desenvolvidas nos serviços-escola (ambulatórios, hospitais e unidades de saúde). Quando a prática ilustra os dilemas, problemas ou conflitos éticos, a conexão entre estudantes e professores é aprimorada. 
Quadro 2. Períodos e temas para as disciplinas de humanidades médicas

\begin{tabular}{|c|c|}
\hline Período & Temas \\
\hline 1 은 & $\begin{array}{l}\text { Relação médico-paciente ante morte e luto; espiritualidade e medicina; drogas (contexto social, } \\
\text { histórico e cultural); educação e direitos humanos; medicalização da vida; dinheiro e economia em } \\
\text { relação com a saúde. }\end{array}$ \\
\hline 20 & Textos hipocráticos; medicina narrativa; paradigmas da medicina ocidental e oriental. \\
\hline 30 & $\begin{array}{l}\text { Formação humanística versus formação técnica; cuidado com o meio ambiente; empatia, } \\
\text { solidariedade, compaixão e cuidado integral; parto humanizado. }\end{array}$ \\
\hline 40 & $\begin{array}{l}\text { Terapias alternativas (benzedeiras, pajés, rezas, ervas etc.); arte e cuidado; dieta e nutrição na } \\
\text { cultura; gênero e transexualidade; ética e trabalho; cuidado de si; cuidado e suicídio. }\end{array}$ \\
\hline 5 운 & $\begin{array}{l}\text { Ética principialista; populações vulneráveis; bioética social; bioética cotidiana; segurança do paciente; } \\
\text { modelos bioéticos de relação médico-paciente. }\end{array}$ \\
\hline 60 & $\begin{array}{l}\text { Ato médico (premissas e limites); medicina defensiva; erro médico; epistemologia do Código de Ética } \\
\text { e da deontologia. }\end{array}$ \\
\hline 70 & Morte encefálica; vivissecção; aborto; fases do luto; eugenia. \\
\hline
\end{tabular}

Vasconcelos ${ }^{20}$ assinala a importância de práticas "alternativas" que rompam com o modelo dominante. O autor aponta três elementos essenciais para transformar o currículo: 1) abordagem de situações pessoais e familiares; 2 ) contato com pacientes e comunidade; e 3) contato com professores e colegas na universidade ${ }^{20}$. A mudança exige espaços pedagógicos que valorizem vivências subjetivas, e, no mesmo sentido, Rios destaca o desafio de relacionar razão e sensibilidade na formação médica ${ }^{21}$. Por fim, Vasconcelos ${ }^{20}$ ainda chama atenção para a importância dos critérios de avaliação, que podem transformar a realidade.

Algumas universidades têm apresentado experiências inovadoras de integração das humanidades médicas. Pode-se citar a Universidade Federal de Pernambuco, campus Caruaru, que criou o Laboratório de Sensibilidades, Habilidades e Expressão a fim de valorizar a percepção de si e o estabelecimento de vínculos como formas de cuidado. Outro exemplo é a disciplina Medicina e Humanidades, da Universidade de São Paulo, que tem como objetivo estimular a percepção do sentido humanístico da prática médica, desenvolvendo a capacidade de reflexão dos estudantes ao introduzir valores, atitudes e habilidades fundamentais para a assistência à saúde.

No dia 18 de outubro de 2018, comemorando o Dia do Médico, o Conselho Federal de Medicina passou a divulgar em seu site o blog de sua Comissão de Humanidades Médicas, intitulado "Humanos". Trata-se de plataforma criada pela autarquia para estimular a sensibilidade do médico, promover o exercício humanístico da profissão e divulgar (...) reflexões e ensinamentos sobre questões éticas ${ }^{22}$.

São várias as iniciativas para alicerçar as humanidades na relação médico-paciente, o que evidencia a necessidade de trocas e diálogos que busquem configurações mais equânimes e inclusivas. Chama atenção a evidência ética-estética-política dessa valorização da dimensão humana. Como apontam os estudantes entrevistados, "se todo mundo tivesse consciência de que tem que tratar o outro como humano, não como 'isso', como 'aquilo', todo mundo já teria na cabeça como tem que tratar alguém" (Grupo Focal 2).

Ainda que não seja unânime, esse interesse tem efeito nas disciplinas de humanidades médicas, inspirando estratégias formativas que valorizam a relação do discente consigo mesmo e com a instituição de ensino. Cada vez mais buscam-se práticas pedagógicas capazes de motivar alunos e professores, resgatar premissas básicas do cuidado de si e do outro, reconhecer as mudanças geradas pelo próprio processo de formação, experimentar o protagonismo e a dimensão coletiva da educação e interferir nos modos de gestão e atenção institucional. Ao mesmo tempo, os estudantes identificam o paradoxo de uma disciplina que visa "humanizar" os futuros médicos:

"Não deveria ter uma disciplina de humanidades. Eu falo com meus amigos e não tem nenhum que não me interrogue: o que é essa disciplina Humanidades Médicas? [risos] Eu falo que é uma aula absurda. Os semideuses da medicina precisam de uma aula para serem humanos. A gente esquece que é humano porque tem um saber, porque estuda seis anos, tem um privilégio ou escolha de passar seis anos com pai ou mãe ajudando e bancando" (Grupo Focal 4).

Deve-se desenvolver estratégias pedagógicas com o intuito de provocar e compartilhar experiências de criação artística como objeto estético-político de comunicação com o mundo. Pode-se, por 
exemplo, propor a confecção de painel com fotos de autoria dos alunos, com tema como "limites e problemas éticos na medicina". Outra possibilidade é criar "portfólio do cuidado" para compilar e sistematizar a vivência individual do discente a partir de narrativa reflexiva, apresentando, por exemplo, o cuidado de um colega de sala de aula durante o semestre, retratando a relação consigo mesmo e com o outro em processo de análise crítica e devidamente fundamentada. Esse portfólio arquitetaria o percurso de aprendizagem com trocas entre colegas, evidenciando avanços, interrogações e dificuldades, propondo síntese provisória da vivência individual e coletiva, formulando questões e avaliando o lugar do "cuidado anônimo".

Independentemente dos métodos, o desafio é construir relações pautadas na atenção e na escuta do outro, incentivando experiências e narrativas de discentes e docentes em interlocução com debates éticos. As vivências narradas, ainda que particulares, permitem a transmissão e o enlace de histórias, ampliando a compreensão e sensibilizando o outro. Essas experiências pessoais, quando passam a ser coletivas, renovam o conhecimento.

\section{Considerações finais}

Humanizar a educação médica é exercício permanente de ressignificação das instituições de ensino superior. Especificamente, trata-se de avaliar problemas do processo de ensino-aprendizagem e desenvolver oportunidades para outras formas de conexão entre docentes e discentes, problematizando questões inerentes à ética médica. Tal abordagem põe em diálogo o paradigma flexneriano e o paradigma ético-estético-político da integralidade, em movimento constante de reflexão sobre a formação, dando luz a cisões entre doutrinas, ideologias e agrupamentos do próprio campo da educação médica.

A dimensão ética demanda participação ativa da comunidade acadêmica, destacando-se, nesse sentido, a relação entre alunos e professores. Reuniões para discutir conteúdos, estratégias de ensino, avaliação e metodologia podem colaborar com a interligação entre teoria e prática e o desenvolvimento de habilidades e atitudes críticas.

Neste estudo foram identificados problemas éticos na relação entre discentes e docentes. Professores muitas vezes esperam "transmitir" o conteúdo aos estudantes, e estes, por sua vez, frequentemente anseiam por "aprendizagem prática" em forma de respostas-padrão. Influi nesse processo a construção de projeto a um só tempo incomum e em comum, com compreensões diversas e difusas dos resultados a serem alcançados e do perfil ético, crítico e reflexivo ideal do médico.

A atual ênfase na relação entre medicina e humanidades faz parte de movimento contra-hegemônico. Construir estratégias e configurações que mantenham o processo educacional avaliativo-formativo-participativo - isto é, linha metodológica que se desenvolva na interseção de diferentes instâncias pode ser uma pista para a invenção construtivista de saberes. Essa dimensão da educação médica deve extrapolar a demanda por "aprimoramento" de conhecimentos sobre a jurisdição do comportamento ético: a integração das humanidades não pode representar mais um alicerce da medicina defensiva apta a evitar ações judiciais por imperícia, imprudência e negligência.

\section{Referências}

1. Gallian D, Pondé LF, Ruiz R. Humanização, humanismos e humanidades: problematizando conceitos e práticas no contexto da saúde no Brasil. Rev Int Humanid Méd [Internet]. 2012 [acesso 10 ago 2018];1(1):5-15. DOI: 10.37467/gka-revmedica.v1.1293

2. Brasil. Ministério da Saúde. 11 a Conferência Nacional de Saúde: o Brasil falando como quer ser tratado [Internet]. Brasília: Ministério da Saúde; 2002 [acesso 4 mar 2020]. Disponível: https://bit.ly/2P2wqKn

3. Brasil. Ministério da Saúde. Humaniza SUS: documento base para gestores e trabalhadores do SUS [Internet]. 4a ed. Brasília: Ministério da Saúde; 2010 [acesso 9 jan 2020]. Disponível: https://bit.ly/3gk20io

4. Conselho Nacional de Educação. Câmara de Educação Superior. Resolução CNE/CES no 4, de 7 de novembro de 2001. Institui diretrizes curriculares nacionais do curso de graduação em medicina. Diário Oficial da União [Internet]. Brasília, 9 nov 2001 [acesso 9 jan 2020]. Disponível: https://bit.ly/3gbjjlR

5. Conselho Nacional de Educação. Câmara de Educação Superior. Resolução CNE/CES no 3, de 20 de junho de 2014. Institui diretrizes curriculares nacionais do curso de graduação em medicina e dá outras providências. Diário Oficial da União [Internet]. Brasília, 23 jun 2014 [acesso 9 jan 2020]. Disponível: https://bit.ly/334JRSe 
6. Rios IC. Humanidades médicas como campo de conhecimento em medicina. Rev Bras Educ Méd [Internet]. 2016 [acesso 20 nov 2018];40(1):21-9. DOI: 10.1590/1981-52712015v40n1e01032015

7. Rios IC. Op. cit. p. 28.

8. Horton MEK. The orphan child: humanities in modern medical education. Philos Ethics Humanit Med [Internet]. 2019 [acesso 28 jul 2020];14(1). DOI: 10.1186/s13010-018-0067-y

9. Stewart KA. Transforming undergraduate global health education through a humanities-focused curriculum. Pedagogy Health Promot [Internet]. 2020 [acesso 28 jul 2020];6(1):9-13. DOI: $10.1177 / 2373379919900534$

10. Shalev D, McCann R. Can the medical humanities make trainees more compassionate? A neurobehavioral perspective. Acad Psychiatry [Internet]. 2020 [acesso 28 jul 2020]. DOI: $10.1007 / \mathrm{s} 40596-020-01180-6$

11. Minayo MCS. O desafio do conhecimento: pesquisa qualitativa em saúde. 14a ed. São Paulo: Hucitec; 2010.

12. Gaskell G. Entrevistas individuais e grupais. In: Bauer MW, Gaskell G, editores. Pesquisa qualitativa com texto, imagem e som: um manual prático. 3a ed. Petrópolis: Vozes; 2002. p. 64-89.

13. Universidade do Vale do Itajaí. Medicina [Internet]. Projeto pedagógico; [s.d.] [acesso 20 nov 2018]. Disponivel: https://bit.ly/2X5tnFp

14. Grisard N. Ética médica e bioética: a disciplina em falta na graduação médica. Bioética [Internet]. 2002 [acesso 2 nov 2018];10(1):97-114. Disponível: https://bit.ly/2BBD6f9

15. Grisard N. Op. cit. p. 100.

16. Barbosa Neto F. As diretrizes curriculares contribuíram para a formação de um médico mais crítico e reflexivo? In: Streit DS, Barbosa Neto F, Lampert JB, Lemos JMC, Batista NA, organizadores. Educação médica: 10 anos de diretrizes curriculares nacionais. Rio de Janeiro: Associação Brasileira de Educação Médica; 2012. p. 127-41.

17. Universidade do Vale do Itajaí. Medicina [Internet]. Disciplinas; [s.d.] [acesso 20 nov 2018]. Disponível: https://bit.ly/3iTq7p8

18. Gomes AP, Rego S. Paulo Freire: contribuindo para pensar mudanças de estratégias no ensino de medicina. Rev Bras Educ Méd [Internet]. 2014 [acesso 12 out 2018];38(3):299-307. DOI: 10.1590/S0100-55022014000300003

19. Lampert JB. Tendências de mudanças na formação médica no Brasil: tipologia das escolas. $2^{a}$ ed. São Paulo: Hucitec; 2009.

20. Vasconcelos EM. Formar profissionais de saúde capazes de cuidar do florescer da vida. In Vasconcelos EM, Frota LH, Simon E, organizadores. Perplexidade na universidade: vivências nos cursos de saúde. São Paulo: Hucitec; 2006. p. 265-308.

21. Rios IC. Humanidades e medicina: razão e sensibilidade na formação médica. Ciênc Saúde Coletiva [Internet]. 2010 [acesso 17 out 2018];15(supl 1):1725-32. p. 1725. DOI: 10.1590/ S1413-81232010000700084

22. Conselho Federal de Medicina. Humanos; blog da Comissão de Humanidades Médicas do CFM [Internet]. Sobre; 2018 [acesso 4 mar 2020]. Disponível: https://bit.ly/2CNQUE7

Correspondência

Rod. Governador Jorge Lacerda, 3.201, Jardim das Avenidas CEP 88906-072. Araranguá/SC, Brasil.

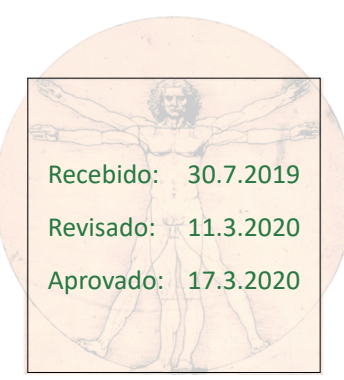

